\title{
UM BREVE PERCURSO HISTÓRICO SOBRE O BUDō: DE ARTE MARCIAL JAPONESA À PRÁTICA ESPORTIVA MUNDIAL
}

\section{A STUDY ABOUT BUD $\bar{O}$ : FROM JAPANESE MARTIAL ART TO WORLD SPORTS PRACTICE}

Narumi Ito*

Resumo: O presente artigo tem como objetivo principal apresentar o conceito de Budō (caminho do guerreiro), traçando um percurso histórico desde o que compreendemos como arte marcial tradicional japonesa até a contemporaneidade. O Budō passou por transformações que causaram alterações em seu significado, sendo hoje considerado uma prática esportiva através de artes marciais como o Aikidō, Judō, Iaidō, Karatê, Kendō e Kyudō e outras. Para tanto, foi de suma relevância a reflexão e discussão em torno do equilíbrio entre os aspectos físico e mental como um de seus princípios, além de aprofundarmos sobre o bushidō (código de honra dos bushi). Desse modo, percebemos que este é um assunto que ainda foi pouco explorado em pesquisas brasileiras e que possui amplo potencial para pesquisas posteriores.

Palavras-chave: Budō. Arte Marcial Japonesa. Tradição. Esporte.

\begin{abstract}
The main objective of this article is to present the concept of Budo (Warrior's Way), tracing a historical path from what we understand as a traditional Japanese martial art to contemporaneity. Budō went through transformations that caused changes in its meaning, being today considered a sport practice through martial arts such as Aikidō, Judō, Iaidō, Karatê, Kendō and Kyudō and others. Therefore, the reflection and discussion on the balance between the physical and mental aspects as one of its principles was of paramount importance, in addition to deepening on the bushido (code of honor of the bushi). Thus, we realize that this is a subject that has been little explored in Brazilian research and that has great potential for further research.
\end{abstract}

Keywords: Budō. Japanese Martial Art. Tradition. Sport.

\section{INTRODUÇÃO}

Este trabalho tem o propósito de refletir, questionar e discutir sobre a temática do Budō e

\footnotetext{
${ }^{*}$ Licenciada em Letras-Inglês pela Universidade do Estado do Mato Grosso (UNEMAT). Mestranda no Programa de Pós-Graduação em Língua, Literatura e Cultura Japonesa - FFLCH (USP). Bolsista FAPESP.

E-mail:<narumiito@usp.br>.
} 
seu percurso histórico, tendo em vista que ele foi base para a criação de diversas artes marciais. Neste sentido, este estudo inicial busca compreender desde a sua essência enquanto arte marcial japonesa tradicional até a sua transformação em prática esportiva global. Para tanto, foi necessário examinar vários pontos da história do Japão, os percursores e mestres que guiaram as artes marciais por muitos séculos até chegarmos as artes marciais que conhecemos atualmente.

O Brasil é o país que mais possui japoneses fora do Japão. De acordo com o censo feito em 2017 e publicado no portal oficial do Governo do Brasil, os dados estatísticos revelaram que há aproximadamente 1,5 milhões de cidadãos de origem japonesa que moram no país. Apesar disso, ainda há muitos temas e questões orientais que deveriam ser mais compreendidas no Brasil, por exemplo, assuntos essenciais que fazem parte da cultura japonesa, mas que ainda não são totalmente esclarecidos para a maior parte dos brasileiros. De modo geral, o Budō representa as artes marciais tradicionais representativas da história do Japão, tendo influenciado diversas outras lutas que estão presentes na vida de muitos brasileiros e diversas pessoas ao redor do mundo.

No século XVII, época do Xogunato Tokugawa, houve a pacificação e unificação do Japão. O Bujutsu deixou de ser uma arte da guerra e passou a ser algo que poderia contribuir para a formação da educação, um equilíbrio entre a mente e o corpo, que posteriormente ganhou uma conotação esportiva (MARTINS \& KANASHIRO, 2010). Na Restauração Meiji (18681912) ocorreu o fim do Xogunato, a sociedade deixou de ser dividida em castas e, por consequência, a classe dos guerreiros e samurais foi extinta.

O Budō, entre outros sentidos, pode ser compreendido como o "caminho marcial" que remete a pensamentos filosóficos, religiosos e corporais concomitantemente. O praticante é capaz de desenvolver a sua personalidade e de contribuir com a sociedade como um todo. (GOMES, 2008). Também é conhecido por se tratar de uma nova versão do Bujutsu (técnica marcial clássica), que apresentava inúmeras regras que os bushi (ou samurais) deveriam seguir em suas lutas.

O conceito de Budō surgiu aproximadamente em 1880, tendo como objetivo assegurar que os ideais filosóficos e culturais dessa prática antiga não fossem perdidos e pudessem ajudar o homem moderno de alguma maneira. A partir daquela época, alguns métodos antigos de treinamento foram reformulados e resultaram no que conhecemos hoje como Judō, Kendō, Kyudō, Karatê, Aikidō, entre outros (FARIAS, 2009). Portanto, o Budō foi inspiração e fonte de várias artes marciais que existem até os dias atuais e que se propagaram por todo o mundo.

De acordo com Takedo Sasaki (2008): “a cultura japonesa é chamada de cultura da forma. 
No cerne da cultura estão as técnicas transmitidas de geração em geração desde os tempos antigos, através de treinamento constante das formas" (SASAKI, 2008, p. 47, tradução nossa). Assim, as artes marciais podem ser classificadas como exemplos de cultura de forma japonesa, pois são fundamentais alguns elementos para a sua prática, como o conjunto, o caso, a mentalidade e muitas vezes a katana (espada).

Outro exemplo de cultura de forma japonesa é a cerimônia de chá, sendo imprescindível os objetos como a tigela, o recipiente, o batedor e a concha feitas de bambu, além das vestimentas especificas para a ocasião e a casa de chá que também tem suas características singulares. No arranjo floral (ikebana), há diversas técnicas e regras básicas no momento de elaborar um arranjo floral, além de princípios que são importantes e que buscam um equilíbrio entre o homem, o céu e a terra.

O Budō continua presente na vida dos japoneses, uma vez que está inserido no currículo de Educação Física das escolas no Japão por meio das artes marciais como o Kendō e o Judō. (HONDA, 2003). É perceptível que os ideais do Budō são relevantes para a história e cultura japonesa, e que as escolas pretendem preservá-los, pois carregam consigo conhecimento milenares e representativos para o país. Além disso, as artes marciais também são importantes para a defesa pessoal e a manutenção de um corpo saudável.

Na modernidade, o Budō é cultivado e praticado por pessoas de todas as idades no Japão e em todo o mundo, não somente por ser um esporte de competição, pois o Budō é uma forma de aprimorar e evoluir a si próprio (ATSUNAGA, 2009). Em resumo, o Budō, assim como a chanoyu (cerimônia de chá japonesa), a ikebana (arte de arranjos florais), o sumiê (técnica de pintura oriental) e o shodō (caminho da caligrafia) fazem parte da cultura tradicional japonesa. Todos esses "caminhos" ou técnicas japonesas possuem ideais grandiosos no que diz respeito ao aprimoramento do ser humano, o desenvolvimento de seu modo de ver a vida e a sua contribuição com a sociedade.

Neste trabalho, usaremos o rōmaji (a romanização do japonês significa literalmente "letra romana"), seguindo as regras do Sistema Hepburn. Foram feitas transcrições fonéticas da língua japonesa para o alfabeto latino (ou romano), levando em consideração que na língua japonesa geralmente são usados três tipos de alfabetos: kanji (ideogramas), hiragana (silabário usado para palavras japonesas) e katakana (silabário usado principalmente para palavras estrangeiras ou onomatopeias). 


\section{BUDō: O EQUILÍBRIO ENTRE O CORPO E A MENTE}

O Budō, assim como as outras artes tradicionais japonesas, trazem consigo ensinamentos transcendentais e vitais para o bem-estar de todo e qualquer ser humano. Muito além de apenas técnicas de guerra ou simplesmente um esporte para o aprimoramento do corpo, demonstra princípios que continuam fazendo sentido e auxiliando no desenvolvimento das pessoas e da sociedade contemporânea. Neste tópico, será discutido sobre a importância do equilíbrio entre a mente e o corpo para a prática de artes marciais.

O primeiro ideograma de $B u d \bar{o}, b u$, significa deter o conflito com armas, isto é, parar a violência através de violência. Apesar de parecer contraditório acabar com a guerra com mais guerra, o segundo ideograma colabora na compreensão, pois $d \bar{o}$ remete ao caminho espiritual, como se fosse uma escada ou um trajeto que levasse o indivíduo para o céu (FROSI, 2012). Isto posto, pode-se concluir que Budo é o "caminho para deter o conflito", pois mesmo com a utilização da força e das armas durante o trajeto do guerreiro, no final, o objetivo principal dele é acabar com a violência e interromper o conflito.

Influenciados pelo código de honra (Bushidō), mestres como Jigoro Kano (1860-1938), fundador do Judō, Gichin Funakoshi (1868-1957), criador do Karatê e Miriheir Ueshiba (18831969), precursor do Aikidō, acreditavam que através do treinamento disciplinado e árduo das técnicas de artes marciais, os praticantes alcançariam o equilíbrio entre a mente, o corpo e o espírito (FARIAS, 2009). As técnicas ensinadas por esses três mestres já se distinguiam dos métodos mortais antigos, que eram comuns durante as guerras. Os novos métodos focavam no aperfeiçoamento dos conhecimentos voltados para a educação e elevação do ser humano.

Conforme o pesquisador Vitor Rosa (2015), “as artes marciais são produtos culturais complexos, cuja prática se pode relacionar com motivações com a defesa, competição, lazer, canalização da agressividade, educação física e social, saúde, ou procura de uma filosofia" (ROSA, 2015, p. 124). Portanto, várias razões explicam o interesse das pessoas pelas artes marciais, podem ser motivos mais objetivos, como defesa pessoal, esporte, lazer, ou a procura de uma filosofia, análogo à relação que muitos indivíduos têm com a religião. Mais espiritual, mental e invisível e que traz muitos benefícios aos olhos de quem cultiva, uma filosofia capaz de gerar satisfação e alegria para a vida dos praticantes. De acordo as palavras do Tiago Frosi (2012):

É preciso alertar que há uma diferença fundamental do Budô com o esporte, especialmente com os outros esportes de luta. No Budô não se quer a 
visualização festiva e espetacularização dos processos que ocorrem com seus praticantes. Não há marcação de recordes e nem igualdade de condições. Há apenas o desenvolvimento do poder para sobreviver a uma situação de conflito real, por isso, temos uma das principais resistências à participação e fomento de competições pelos praticantes mais "tradicionais", pois a competição esportiva retira o elemento realístico do treinamento e o substitui por gestos quase inofensivos, para que a integridade do adversário realmente não seja abalada (FROSI, 2012, p. 41).

Há uma polêmica em torno de sua esportivização. Por um lado, há grupos de pessoas que almejam manter o Budō em sua versão tradicional, e acreditam que a melhor opção seria a não esportivização, uma vez que ela acaba mudando e alterando muitas regras que não são mais convenientes ou viáveis para a modernidade. Por outro lado, existem pessoas que compreendem a importância do Budō na história, mas acreditam que a esportivização é necessária e válida para que essa arte secular possa continuar viva e de alguma forma acrescentando e contribuindo com a sociedade.

Frosi (2012) esclarece algumas diferenças entre o Budō e o esporte, sobretudo nas lutas. $\mathrm{O}$ autor explica que para os praticantes tradicionais, o esporte acaba tirando muito do que o Budō significa, a sua essência, uma vez que na luta clássica não havia igualdade de condições e nem marcação de recordes, já que o objetivo não era ser visto ou filmado. Basicamente, a arte marcial envolvia lutar e sobreviver em circunstâncias reais de conflito. Todavia, com o final das guerras, a casta desses guerreiros deixou de ser útil, e não houve outra maneira a não ser torná-lo um esporte, para que fosse possível a sobrevivência da sua história. De acordo com Carlos Martins e Cláudia Kanashiro (2010) sobre a definição de esporte moderno: A expressão "esporte moderno" foi utilizada pela primeira vez por Norbert
Elias e Eric Dunning para demarcar a diferença com o esporte antigo e
tradicional. A maioria dos esportes que conhecemos e praticamos hoje são
considerados esportes modernos. Os esportes modernos possuem as seguintes
características: diminuição do grau de violência, codificação de regras e das
práticas, igualdade formal entre os jogadores, espaços e tempos próprios,
desvinculando-se de rituais religiosos (secularização) (MARTINS \&
KANASHIRO, 2010, p. 638).

Os autores Martins \& Kanashiro (2010) elucidam o conceito de esporte moderno, tendo em vista que foi usado pela primeira vez pelos sociólogos Norbert Elias e Eric Dunning com o intuito de distinguir os dois tipos. Conforme os estudiosos, o esporte moderno tende a ter o grau de violência diminuído, geralmente ocorre a criação ou reformulação do código de práticas que 
rege o determinado esporte, há também a instituição de igualdade em tempo e espaço entre os praticantes. Além disso, acontece a secularização, isto é, a perda da força religiosa em relação aos esportes modernos, tornando-os mais acessível aos leigos e permitindo que mais pessoas pudessem participar dos esportes. Conforme Takedo Sasaki (2008), o Budō possui uma prática importante denominada Shugyo, que pode ser compreendida como uma forma de equilibrar a mente e o corpo, o autor definiu-a:

Shugyo tem um significado importante na mentalidade japonesa, especialmente em relação aos problemas da mente e do corpo. Shugyo, em geral, significa treinamento prático para melhorar o próprio espírito e a personalidade. Em outras palavras, "matéria e lógica, corpo e espírito" são inseparáveis. Além disso, eles têm a característica de "nada". Portanto, através do treinamento físico, a prática tem o objetivo de treinar o espírito e a melhoria da personalidade na vida real (SASAKI, 2008, p. 48, tradução nossa).

Segundo o autor, Shugyo é um conceito importante para a cultura japonesa de modo mais amplo, já que significa uma técnica de treinamento capaz de aprimorar não só o corpo, mas também o espírito e o interior de quem pratica. Essa técnica e outras vistas no Budō possivelmente têm raízes na filosofia zen budista, assim como em diversas artes marciais e artes japonesas, pois todas elas são entendidas como um caminho para o zen.

Conforme André Farias (2009), a relação entre o zen budismo e o bushidō é permeada pelo ensinamento de não temer o perigo ou a morte, além de ter um espirito desapegado em relação à vida. Nas palavras do estudioso: "o zen budismo trata do objetivo de alcançar a iluminação espiritual, por meio da aceitação de que a vida é sofrimento. Essa religião levou ao samurai tranquila confiança, submissão pacífica ao inevitável e desdém à vida além de uma familiaridade com a morte" (FARIAS, 2009, p. 50).

Neste sentido, o zen budismo funcionou para os guerreiros como um "propósito de vida", pois os bushi acreditavam na iluminação espiritual se aceitassem todos as dores que a vida poderia oferecer a eles. Dessa forma, a classe dos samurais lutava sem o medo de perder a vida nas batalhas, pois tinham a confiança de que a morte não era o fim de tudo, e sim um modo de atingirem a paz e a tranquilidade que tanto almejavam. Para Leornard (1973) \& Sugai (2008) apud Martins \& Kanashiro (2010), sobre a iluminação espiritual:

O Zen, diferentemente de outras modalidades do budismo e do pensamento ocidental, não enfatiza a importância do conhecimento abstrato e especulativo, da lógica, dos sutras sagrados ou mesmo a leitura dos mesmos pelos eruditos. 
O Zen afirma que esse caminho é uma ascese pessoal, corporal e espiritual. É uma metáfora do prático, sistemático e místico, como expressão da cultura oriental. A ideia central do Zen é a súbita iluminação, essa iluminação pode advir como resultado de intensa disciplina (LEONARD, 1973 \& SUGAI, 2008 apud MARTINS \& KANASHIRO, 2010, p. 638).

Conforme os autores, o zen budismo se difere de outras linhas do Budismo e do pensamento ocidental de modo geral, pois não incentiva o conhecimento através ideias palpáveis e lógicas. Por outro lado, segue o pensamento oriental e tem a iluminação como "ponto de chegada", como um objetivo maior a ser alcançado. Desse modo, o caminho pode ser compreendido como prático e sistemático, ao mesmo tempo que é místico e espiritual, o trajeto é individual, onde o praticante une o corpo e o espirito com muita disciplina para merecer a iluminação.

\section{BREVE PERCURSO HISTÓRICO SOBRE O CAMINHO DO GUERREIRO}

Os bushi ou samurais existem desde o Japão Feudal e, ao longo do tempo, sofreram transformações e alterações em suas funções na sociedade. No início, eles serviam como cobradores de impostos ou administradores de terras, já entre os anos de 930 a 1877 ganharam destaque como soldados da aristocracia imperial e ocupavam funções militares. Neste contexto, esse segundo tópico tem o propósito de explorar como o caminho do guerreiro e o código de honra (bushidō) continuam preservando alguns valores até a contemporaneidade.

No Xogunato Tokugawa (1603-1868), época da ditadura feudal militar, os conceitos de Budōe Bushidō eram usados como sinônimos, pois representavam o estilo de vida dos samurais. (ATSUNAGA, 2009). No entanto, compreendemos na modernidade que Budō é o caminho marcial de origem japonesa, uma versão atualizada do Bujustu. O Bushidō, por outro lado, está mais ligado a um código de honra do guerreiro, capaz de guiá-lo a praticar determinadas condutas e orientá-los para alcançarem a iluminação espiritual.

No período Edo, ainda sob o governo da família Tokugawa, foi um tempo considerado de paz e harmonia, quando o Japão desenvolveu um mercado nacional e uma economia monetária. A classe dos samurais desta época acabou perdendo espaço e começou a procurar outros meios de subsistência, alguns se dedicaram a pintura, ao artesanato, ao chá ou outras artes japonesas (ROSA, 2015). 
A partir da Restauração Meiji (1868-1912), os conceitos de Budō e Bushidō ganharam sentidos distintos, sendo que o último foi importante como um suporte espiritual para os japoneses patriotas. A obra Bushidō: a alma do samurai (1899), do escritor japonês Nitobe Inazō ajudou a popularizar no ocidente os valores que regem a conduta de um guerreiro. Em relação ao Budō, o conceito adquiriu uma nova nomenclatura através da criação de diversas artes marciais modernas.

Segundo Vitor Rosa (2015), em relação ao significado de Budō na contemporaneidade: "A palavra Budō conota uma certa ideia de "japonitude", ou seja, o termo abrange as práticas que pertencem à 'tradição japonesa"” (ROSA, 2015, p. 126-127). Neste sentido, o Budō, assim como as outras artes marciais ou demais "caminhos" podem ser interpretados como metáforas do que o ocidente conhece como cultura ou tradição oriental. Portanto, esse termo e as artes marciais de modo geral são símbolos fortes que carregam consigo a história do Japão, sobretudo o que os japoneses quiseram revelar ou disseminar sobre a tradição do Japão para os ocidentais.

Em relação ao código de honra dos guerreiros, de acordo com John Stevens (2005): “em um manuscrito da Escola de Kahima Shin, há dez males para um praticante do budō, os artistas marciais não devem ter essas falhas de caráter: Insolência, confiança excessiva, ganância, raiva, medo, dúvida, suspeita, hesitação, desprezo e vaidade" (STEVENS, 2005, p. 54). Todos esses males foram compilados em um manuscrito pela escola de artes marciais Kahima Shin e demonstram as falhas de caráter possíveis em todo e qualquer ser humano. Conseguir superálos seria bom tanto para os guerreiros quanto para qualquer indivíduo que compõe a sociedade, trazendo benefícios para si próprio e para todos a sua volta.

Este talvez seja o motivo de diversos livros ou filmes que tratam de códigos de samurais serem tão vendidos e alcançarem um grande sucesso. Um exemplo disso é Musashi: o livro dos cinco anéis (1645), escrito por um dos samurais mais famosos: Miyamoto Musashi. Chegou a vender aproximadamente 120 milhões de exemplares em todo o mundo (AMAZON, 2020).

A produção cinematográfica "Samurai: O Guerreiro Dominante" é uma trilogia de filmes lançada em 1954 no Japão, dirigida por Hiroshi Inagaki, que se destacou por ganhar o Oscar de melhor filme estrangeiro em 1955 (GARCIA, 2016). O filme e o livro apresentados são apenas dois exemplos que revelam como os samurais japoneses possuem uma imagem atraente e influente para as pessoas até a modernidade. Conforme John Stevens (2005), Miyamoto Musashi criou sete desafios para os praticantes das artes marciais:

1) Experimente o frio, o calor e a chuva escalando altas montanhas e atravessando vales profundos. 2) Descanse em campos abertos e durma nas 
montanhas. 3) Nunca guarde dinheiro ou comida e nunca use roupas quentes. 4) Viaje para qualquer lugar para participar das disputas. 5) Resida em cemitérios, casas assombradas ou entre feras selvagens. 6) Associe-se a perigosos malfeitores. 7) Viva do lado do produto da terra, entre agricultores (STEVENS, 2005, p. 21).

Segundo o espadachim Musashi, os guerreiros deveriam conseguir passar por essas sete adversidades, mas vale ressaltar que esses conflitos não são mais necessários para o homem moderno. Por qual razão o sujeito do século XXI iria se submeter a demasiado frio ou calor? Ou dormir em montanhas? Hoje, não guardar dinheiro ou comida é algo irresponsável e indesejável. Não tem sentido morar entre selvagens ou em lugares insalubres como cemitérios e casas mal assombradas. E por qual motivo as pessoas viveriam perto de pessoas perigosas ou malvadas?

No entanto, é preciso considerar que Miyamoto Musashi (1584-1645) viveu em outro contexto histórico, vivenciou diversas guerras e obstáculos que a sociedade atual já não tem acesso. Apesar de não precisarmos necessariamente resolver esses problemas propostos pelo guerreiro, temos outros desafios que podem ser solucionados ou resolvidos com a mesma estratégia ensinada por Musashi, imitando a perspicácia que ele tinha para prever situações e aprender com tudo o que tinha ao seu redor.

Outro espadachim brilhante que deixou como herança alguns princípios norteadores para a posteridade foi Yagyu Renya (1625-1694), pertencente ao clã Yagyu. Ele criou sete princípios que envolvem a força da mente e nos ensina alguns métodos espirituais que podem ajudar no treinamento e no aprimoramento da força física e mental, a maioria requer muita disciplina, dedicação e autoconhecimento:

1) Permaneça no centro: este é um princípio do meio-termo: permanecer no centro físico de um lugar e centrado no corpo e na mente. 2) Desponha a espada (aprenda a fazer com que o distante fique próximo: esta é a mesma condição de estar "sem espada". Se a mente estiver vazia pode-se agir espontaneamente e conter todo ataque dentro da sua própria esfera. 3) Remova o eu (não ataque o seu oponente): assim que surge o desejo de vencer, perdese a perspectiva e tenta-se forçar a situação, o que pode resultar em derrota. 4) Harmonize o hara e o senaka (a parte da frente e a de trás constituem uma superfície única: significa usar o corpo inteiro como um todo unificado, de maneira rítmica. 5) Esqueça o seu corpo: não é bom estar consciente demais das suas dores. 6) Cumprimente o seu oponente: quando vier um ataque, movimente-se para enfrenta-lo de maneira audaz e sem medo. 7) Pratique sozinho: estando em pé ou sentado, acordado ou dormindo, em público ou a sós (STEVENS, 2005, p. 29). 
A primeira instrução de Renya aborda a necessidade de ficar no centro, ou seja, manter um equilíbrio entre a mente e o corpo, sendo esse um princípio vigente até a atualidade e ensinado nas escolas de artes marciais. $\mathrm{O}$ espadachim ensina a esvaziar a mente, pois desse modo o praticante é capaz de se concentrar e ser capaz de completar os golpes de forma mais plena e confiante. A terceira lição diz respeito a "remover o eu", e pode ser entendido como manter o foco na batalha, sem se dispersar, pensando no desejo de vencer, porque isso pode prejudicar e acabar levando a derrota.

O ensinamento continua propondo uma harmonização, que acontece no corpo do guerreiro. Renya destaca a importância de saber usar todas as partes do corpo, tanto a frente quanto atrás, para que o corpo lute em conjunto, de uma maneira disciplinada e preparada para todos os golpes possíveis do inimigo. O quinto princípio indica que os aprendizes esqueçam do seu corpo, isto é, não lembrem das dores que estão sentido durante a luta, pois isto pode afetálos e levá-los a morte ou perda. Na sexta instrução, o mestre sugere que os guerreiros cumprimentem seus oponentes e em seguida iniciem a luta sem temor, algo que ainda é comum nas artes marciais modernas.

A última dica do espadachim é sobre a prática solitária, indicando que o treinamento físico deve ocorrer em pé ou sentado, acordado ou dormindo, em público ou sós. Dessa maneira, percebemos como são princípios que exigem bastante disciplina do indivíduo, assim como as lições de Musashi e o código de honra desenvolvido pela escola Kahima Shin sobre os dez males para um praticante do budō. Na atualidade, essas instruções também foram adaptadas, já que a budō deixou de ser uma arte marcial fatal e se tornou um esporte. Levando em consideração a postura de um bushi tradicional, de acordo com Atsunaga (2009), ele deveria:

Só ter habilidade marcial não fez do bushi um guerreiro. Independentemente de quão habilidoso fosse um bushi nas artes marciais, ele não teria utilidade alguma em batalha se tivesse uma mente fraca. Ser verdadeiramente forte não era apenas uma questão de força física, mas também força mental. Através dos horrores da guerra, os bushi foram capazes de descobrir muitos tipos diferentes de força. Alguns eram tangíveis e outras não. Ao aderir aos ideais codificados como bushidô, buscou-se desenvolver seu atributo pessoal e viver uma vida de significado e virtude (ATSUNAGA, 2009, p. 37, tradução nossa).

Conforme Atsunaga (2009) a força física sozinha não era suficiente para um guerreiro, pois durante a guerra, os samurais desvendaram diversos tipos de forças, sendo algumas palpáveis como a força física e outras não, como a força mental e espiritual. O bushidō ou 
código de honra dos bushi foi preservado até a contemporaneidade e é prova da apreciação que os samurais têm pelo equilíbrio entre o físico e o mental. Esse equilíbrio também permite que os guerreiros tenham uma vida mais significativa e repleta de realizações, inclusive, não é apenas uma virtude almejada pelos bushi, mas por muitas pessoas ao redor do mundo.

Desse modo, foi possível compreender nesse tópico um pouco mais sobre a valorização de uma mente forte para os bushi. O caminho do guerreiro no transcorrer da história precisou sofrer inúmeras adaptações e atualizações para que pudesse continuar presente até a modernidade. Apesar de ser um assunto polêmico, uma vez que algumas pessoas mais tradicionais pensam que a disseminação do Budō pode ser algo negativo e causar a perda da tradição. Isto não significa que tenha perdido a sua essência, pois os samurais possuem uma história inigualável e muito representativa para a cultura japonesa.

\section{DE ARTE MARCIAL JAPONESA À PRÁTICA ESPORTIVA GLOBAL}

Este terceiro tópico propõe problematizar a transformação que o Budō sofreu, de arte marcial tradicional japonesa à sua prática esportiva global. A sua chegada no Brasil o ocorreu após o primeiro navio de imigrantes japoneses desembarcar no porto de Santos em 1908. A sua institucionalização aconteceu apenas em 1933, juntamente com a inauguração da Associação Brasileira de Judō e Kendō, chamada "Hakoku Ju-Kendo Ren-Mei” (FARIAS, 2009). Um fato importante é que nos dias atuais existe muita demanda de alunos que buscam as artes marciais japonesas, sendo um dos maiores seguimentos de atividade física no Brasil. Segundo Atsunaga (2009) sobre essa globalização:

As artes tradicionais do Japão (bugei ou bujutsu) evoluíram a partir das
experiências e da cultura da classe de guerreiros feudais conhecida como bushi
ou samurai. As artes marciais tornaram-se cada vez mais "esportivas" no
processo de modernização do Japão no período Meiji (1868-1912), e
especialmente no pós-guerra. Nos últimos tempos, o budô japonês viu um
grande aumento de participantes em todo o mundo, chegando a dezenas de
milhões. Nenhuma outra forma de cultura tradicional japonesa pode se
orgulhar de uma disseminação tão bem-sucedida em escala internacional. No
entanto, não é tarefa simples garantir que a essência do budô seja mantida à
medida que se estabelece em todo o mundo (ATSUNAGA, 2009, p. 41,
tradução nossa).

O autor explica sobre a evolução das artes japonesas, que passou pelo processo de 
modernização na Era Meiji (1868-1912), deixando de lado algumas técnicas e métodos fatais e desenvolvendo metodologias leves e comuns em esportes. Atsunaga (2009) reflete sobre o aumento de praticantes das artes marciais que nasceram através do Budō e sua disseminação mundial. Apesar de ser uma propagação bem-sucedida em todo o mundo, torna-se mais complexo e difícil manter a essência do Budō, devido ao seu crescimento "descontrolado".

Segundo Atsunaga (2009) seria um problema esquecer os valores que regem o caminho do guerreiro, uma vez que se trata de uma arte japonesa que faz parte de sua tradição e história. Apesar de se tornar inviável enquanto arte de guerra, se adaptou e se transformou em uma prática esportiva extremamente conhecida em todo o mundo. Além dos ideais filosóficos que essas lutas possuem, os esportes também ajudam na manutenção da saúde física e mental, sendo uma atividade muito procurada nos últimos tempos pela sociedade.

Em relação a como surgiram as novas artes, tendo como influência o Budō, o japonês Jigoro Kano (1860-1938) se destacou por desenvolver o Judō, conservando e respeitando os valores tradicionais do Japão. Conforme Atsunaga (2009): “Judō foi desenvolvido como um meio para as pessoas fortalecerem suas mentes e corpos, tornando-se 'cidadãos robustos', capazes de desempenhar um papel positivo na melhoria da sociedade" (ATSUNAGA, 2009, p. 27, tradução nossa). Dessa maneira, Kano foi capaz de selecionar partes do Budō que poderiam ser uteis para a sociedade e para os cidadãos e criou o $J u d \bar{o}$, tendo novos objetivos e métodos. Atsunaga (2009) contribui mais uma vez, explicando que:

Kano notou particularmente o condicionamento físico e mental tradicionalmente empregado pelas escolas de jujutsu do século XVII. Ao combinar os ideais japoneses tradicionais com a educação física ocidental moderna, ele criou com sucesso um novo sistema de educação física baseado na fusão de conhecimentos antigos e novos. Ao eliminar os perigosos movimentos de combate do jujutsu, tais ataques e o perigoso kansetsuwaza (travas nas articulações), ele aperfeiçoou um método para a livre troca de técnicas em lutas denominadas randori (ATSUNAGA, 2009, p. 32, tradução nossa).

Portanto, Kano foi um dos pioneiros em unir conhecimentos antigos com os novos e criar uma arte marcial tendo como base os ideais japoneses tradicionais, juntamente com a educação física ocidental moderna. Para tanto, o educador desvencilhou a noção de arte marcial com perigosos movimentos do Jujutsu, transformando-os em técnicas de lutas randori, uma luta que não vale nenhum ponto, onde os jogadores precisam apenas colocar em prática tudo o que aprenderam com seus mestres, treinando e fixando os golpes e as técnicas. 
A sobrevivência do caminho do guerreiro até a modernidade somente aconteceu devido as suas adaptações, deixando para trás combates que ceifavam vidas. A única forma viável foi introduzir as artes marciais no currículo escolar japonês, onde foram base para metodologias inovadoras. Segundo Cynarski e Obodynski (2009) apud Rosa (2015, p. 128): "atualmente, o Budō é percebido como uma forma moral não agressiva, um meio educacional, uma arte de vida ou um antigo normativo sistema de Bushidô - o código de honra da cavalaria japonesa".

Foi possível refletir neste tópico como o Budō foi e continua sendo uma arte marcial que sobreviveu no tempo e no espaço, pois apesar da sua existência remeter ao Japão Feudal, quando os samurais tinham outros propósitos, ele permanece vivo e presente na vida de muitas pessoas em diversos países. Para que isso pudesse acontecer, teve que passar por muitas mudanças ao longo do tempo, teve que se atualizar e modernizar suas técnicas. No entanto, podemos perceber que as artes que ficaram no seu lugar continuam mantendo e divulgando a sua essência, que também carrega com ela a história, a tradição e a cultura japonesa.

De acordo com o site do Ministério das Relações Exteriores do Japão (2020), “aos estudantes dos 3 últimos anos do ensino fundamental, tanto garotos como garotas, era requerido a escolha de uma dentre três artes marciais - sumō, judō e kendō - como matéria curricular, a partir de abril de 2012". É possível comparar esses esportes com o futebol, vôlei, handebol ou basquete no Brasil, que são práticas comuns nas aulas de educação física no país. Introduzir essas artes marciais no currículo faz com que os alunos involuntariamente conheçam a história e a tradição do Budō através de esportes atualizados.

O Judō ou "caminho gentil" foi desenvolvido pelas escolas Tenshin Shinyo e Kito, seguindo as atualizações realizadas por Kano Jigoro, e foi um dos esportes japoneses que mais ganhou destaque mundialmente. Um fato que deve ser comemorado foi a criação da Federação de Judô Mundial em 1952 e em 1956, Tóquio recepcionou o primeiro Campeonato Mundial de Judô. Nas Olimpíadas de Tóquio, que ocorreu em 1964, o judō se tornou um esporte olímpico tanto para homens quanto para as mulheres. De acordo com a Embaixada do Japão no Brasil (2020), hoje, o Judô é praticado por mais de 5 milhões de pessoas ao redor do mundo.

Outro esporte que merece destaque é o Aikidō, ele se originou através da escola Daito de Jujutsu, fundada por Minamoto Yoshimitsu (1045-1127) e Ueshiba Morihei (1883-1970), famoso por ter aprimorado as técnicas do Aikidō que são praticadas atualmente. O Judô e o Aikidō têm muitos pontos em comuns, no entanto, o último não envolve agarrar as mangas e o colarinho do adversário, mas sim tirar vantagem das fraquezas nos punhos e nos braços dos oponentes. Outro fator que diferencia o Aikidō é que os jogadores não participam de torneios e 
competições, as técnicas são voltadas para a autodefesa, por isso, é um esporte muito praticado por mulheres e por pessoas que trabalham com segurança. (Embaixada do Japão no Brasil, 2020).

O Kendō possivelmente herdou a tradição que os samurais tinham com as espadas. Em 1952, foi desenvolvida a Federação Geral de Kendō do Japão, dando ênfase para o seu lado educacional, ele foi introduzido nas escolas e ganhou peso como esporte. A shinai (espada de bambu) é um utensílio protagonista nas batalhas, os praticantes também usam equipamentos de proteção desde a cabeça até o quadril. Basicamente, os jogadores precisam atingir a cabeça, o tronco, quadril ou garganta do oponente para obter pontuações e vencer a partida.

\section{CONSIDERAÇÕES FINAIS}

Este trabalho buscou problematizar a história do Budō, desde a sua compreensão enquanto arte marcial japonesa tradicional até seu reconhecimento como prática esportiva global. Após pesquisas, foi possível perceber que ainda existem poucos trabalhos, no que tange a artigos, trabalhos de conclusões de cursos, dissertações e teses sobre a temática do Budō ou outras artes marciais japonesas. Sobretudo em Língua Portuguesa, por isso usamos alguns autores que publicaram em inglês e em espanhol para a construção deste artigo.

O Budō foi como uma base para as demais artes marciais modernas, ele influenciou e contribuiu na criação delas. Para tanto, foi extremamente importante o aprofundamento dos subtópicos relacionados como ao tema: Budō: o equilíbrio entre o corpo e a mente, já que se trata de uma arte japonesa que guarda muitos conhecimentos em torno do zen budismo. Esse equilíbrio proposto nas batalhas nos chamou a atenção, uma vez que também faz parte de um princípio relativamente moderno, pois muitas pessoas procuram esse equilíbrio espiritual, ser capaz de lidar com os problemas do corpo e da mente e conseguir superá-los.

No segundo tópico, nos propomos a investigar o caminho do guerreiro no transcorrer da história, uma vez que, o Budō tem raízes no Japão Feudal e o seu conceito passou por vários deslocamentos de sentido e sobreviveu ao tempo e ao espaço. Dessa forma, pode até ser considerado como uma arte japonesa atemporal e universal, pois ela não se restringe a ser uma arte marcial tradicional do Japão, mas atravessou as expectativas e chegou a lugares e até pessoas que não se era esperado.

No terceiro e último tópico trouxemos questões relevantes em torno do caminho do guerreiro enquanto uma prática esportiva global, já que através dele, surgiram artes marciais 
como o Aikidō, Jud̄o e Kendō. Todas essas lutas são reconhecidas e praticadas internacionalmente e são provas de que o Budō tem um potencial imenso para sobreviver e ensinar ao longo do tempo. Portanto, este trabalho ainda tem outro objetivo final, que é abrir espaço para que mais pesquisadores se envolvam pela temática das artes marciais e pelo Budō, e possam contribuir com pesquisas nesse âmbito, já que ainda infelizmente se limita a poucos trabalhos, apesar da grandiosidade de questões que o assunto é capaz de oferecer.

\section{Referências Bibliográficas}

ATSUNAGA, H. et al. Budo: The Martial Way of Japan. Tokyo: Nippon Budokan, 2009.

BRASIL. Site do Ministério das Relações Exteriores do Japão. Disponível em: <https://www.br.emb-japan.go.jp/cultura/artesmarciais.html>. Acesso em 30 de junho de 2021.

Do: a essência da cultura japonesa. São Paulo: Centro de Chado Urasenke do Brasil, 2004.

ESPARTERO, Julián; VILAMÓN, Miguel; GONZÁLEZ, René. Artes marciales japonesas: prácticas corporales representativas de su identidad cultural. In: Rev. Movimento, Porto Alegre, v. 17, n. 03, p. 39-55, jul/set de 2011.

FARIAS, André Alves. A influência do Zen budismo nas artes marciais japonesas no Brasil. 2009. Dissertação (Mestrado em Ciências da Religião) - Pontifícia Universidade Católica de São Paulo, São Paulo, 2009. Disponível em: <https://sapientia.pucsp.br/handle/handle/2118> . Acesso em 21 de junho de 2021.

FIGUEIREDO, Abel. The Object of Study in Martial Arts and Combat Sports Research Contributions to a Complex Whole. In: Cynarski, Wojciech (ed.) Martial Arts and Combat Sports - Humanistic, p. 20-34, 2008. Disponível em: <https://explore.openaire.eu/search/publication?articleId=od2017::e58d740341ad3ef214c038 1dd86d6a09>. Acesso em 18 de junho de 2021.

FROSI, Tiago Oviedo. Uma história do karate-do no Rio Grande do Sul: de arte marcial a 
prática esportiva. Dissertação de Mestrado em Ciências do Movimento Humano - Escola de Educação Física da Universidade Federal do Rio Grande do Sul, 2012.

; OLIVEIRA, M. A. O bushido na prática: o caso da educação em valores no karate shotokan. In: DOS SANTOS, S. L. C. Bushido e artes marciais: contribuições para a educação contemporânea. Curitiba: CRV, 2019, p. 115-132. Acesso em 16 de junho de 2021.

GARCIA, Demian. O som do chanbara. In: Revista de cinema Hatari, Curitiba, v.3, n.3, p. 3039 , 2016. Disponível em:

http://periodicos.unespar.edu.br/index.php/hatari/issue/view/175/showToc>. Acesso em 24 de junho de 2021.

GOMES, Fábio José Cárdias. Quatro histórias e uma epifania: estudos indisciplinares acerca do budô japonês. In: Rev. Dialogia, São Paulo, v. 7, p. 41-51, 2008.

HONDA, Sotaro. Budô ou esporte? concepções concorrentes do Kendo no currículo japonês de educação física do ensino médio. Tese de doutorado, Universidade de Gloucestershire, 2003. Disponível em: 〈http://eprints.glos.ac.uk/3096/>. Acesso em 20 de junho de 2021.

MARTINS, Carlos José; KANASHIRO, Cláudia. Bujutsu, Budô, esporte de luta. In: Rev. Educ. Fis. (Online), Rio Claro, v. 16, n. 3, p. 638-648, setembro de 2010. Disponível em: <http://www.scielo.br/scielo.php?script=sci_arttext\&pid=S198065742010000300011\&lng=en $\& n r m=i s o>$. Acesso em 24 de abril de 2021.

NAGY, Stephen Robert. Japanese Martial Arts as Popular Culture: Teaching Opportunity and Challenge. In: Asian Studies III (XIX), 1 (2015), pp. 83-102. Disponível em: $<$ https://www.researchgate.net/publication/281536518_Japanese_Martial_Arts_as_Popular_C ulture_Teaching_Opportunity_and_Challenge>. Acesso em 20 de junho de 2021.

ROSA, Vitor. Perspetivas e entendimentos dos praticantes portugueses de karaté sobre o conceito de Budô, In: Revista de Artes Marciales Asiáticas. Volume 10, 124-134, julho/dezembro de 2015.2 Disponível em: <http://revpubli.unileon.es/ojs/index.php/artesmarciales>. Acesso em 21 de junho de 2021. 
SASAKI, Takedo. Budo (the martial arts) as Japanese culture. The outlook on the techniques and the outlook on the human being. In: Archives of Budo, 2008, v. 4, p. 46-49. Disponível em: <https://www.researchgate.net/publication/298567055_Budo_the_martial_arts_as_Japanese_c ulture_The_outlook_on_the_techniques_and_the_outlook_on_the_human_being>. Acesso em 21 de junho de 2021.

STEVENS, John (org.). Segredos do budô: ensinamentos dos mestres das artes marciais. Tradução de Maria Tereza Quirino. São Paulo: Cultrix, 2005.

UESHIBA, Morihei. Budô: Ensinamentos do Fundador do Aikidô. São Paulo: Cultrix, 1991. 